\title{
Air quality control on in vitro fertilization outcomes in assisted reproduction laboratories: a systematic review
}

\author{
Bruna Sabbag Pontes ${ }^{1 *}$, Marília Leão Pereira Resende ${ }^{1}$ Eduardo Camelo de Castro \\ 'Pontifícia Universidade Católica de Goiás (PUC), Faculdade de Medicina, Ambulatório de Infertilidade, Goiânia, GO, Brazil
}

\section{Abstract}

Objectives: Embryology laboratories' air quality affects the success of human assisted reproduction. In this paper we made a review of studies that assessed the importance of air quality control of embryology laboratories in the success of assisted human reproduction. Methods: A systematic review was made with studies presented in the following database: PUBMED, Lilacs and Scielo submitted. The researched articles refer to the years 1996 to 2016, in Portuguese, English and Spanish. The keywords were air quality control, in vitro fertilization, embryology, assisted human reproduction, laboratory environment, volatile organic compounds and clean room. Results: Thirty three articles were found. From these, eight studies fulfilled the inclusion criteria. All of them used air filters. Conclusions: The reviewed studies show a trend of improvement in pregnancy rates due to the introduction of filters in IVF laboratories. Apparently, the greater the level of control of environmental pollution and elimination of VOCs.

Keywords: Air quality; in vitro fertilization; HEPA filter; VOC filter.

\section{Introduction}

In the last decades there was a significant increase in the number of assisted reproduction centers. Brazil is slowly moving forward towards an appropriate regulation for the operation of those laboratories. For example, while some centers perform the oocyte pick up in an operation room, others have built a room with positive air pressure and specific filters aiming to avoid the contact of gametes with chemical and volatile products.

Several factors may interfere in the air quality of IVF laboratories and must be followed with periodic records, readjustments and monitoring of the operation for an effective environmental control. Temperature, air humidity, atmospheric composition (amount of solid microscopic pollutants and volatile organic compounds), among others items are observed. ${ }^{1}$

The High Efficiency Particulate Arrestance (HEPA) filters are very effective for solid microscopic pollutants and the activated carbon or potassium permanganate filters for the volatile organic compounds (VOC). According with Bento and Steves, ${ }^{2-4}$ the removal of VOC should be an integral part of the air cleaning in IVF environments.

The aim of this study was to do a systematic review of studies that evaluated the impact of air quality in IVF laboratories on the outcomes of human assisted reproduction.

Financial support: None.

Conflicts of interest: None.

Submitted: May 31, 2017.

Accepted: October 18, 2017.

This study carried out at the Ambulatório de Infertilidade, Faculdade de Medicina, Pontifícia Universidade Católica de Goiás (PUC), Goiânia, GO, Brazil.

Copyright Pontes et al. This is an Open Access article distributed under the terms of the Creative Commons Attribution License, which permits unrestricted use distribution, and reproduction in any medium, provided the original work is properly cited. 


\section{Materials and methods}

It was performed a systematic review of literature. The key words applied for research were "air quality control", "in vitro fertilization", "embryology", "assisted reproduction", "laboratory environment", "volatile organic compounds" and "clean room".

The databases Pubmed, Lilacs and Scielo, articles in English, Portuguese and Spanish between 1996 and 2016 were consulted. Two blinded and independently authors selected the studies with proper methodology. Cases in which there was disagreement, the opinion of a third author was utilized. Following that, the tabulation, analysis and interpretation of the data for the review construction were made.

The clinical trials which related the clinical pregnancy rates when the IVF was performed in a room with better air quality control were included. These rooms could have any kind of barriers against pollutants, such as HEPA or VOC filters. Studies where animal models were used, or when only the internal air of the incubator was assessed was excluded.

The reading of the abstracts was the first step. Following that, a full reading was made and the references of those articles were included in the study (Figure 1).

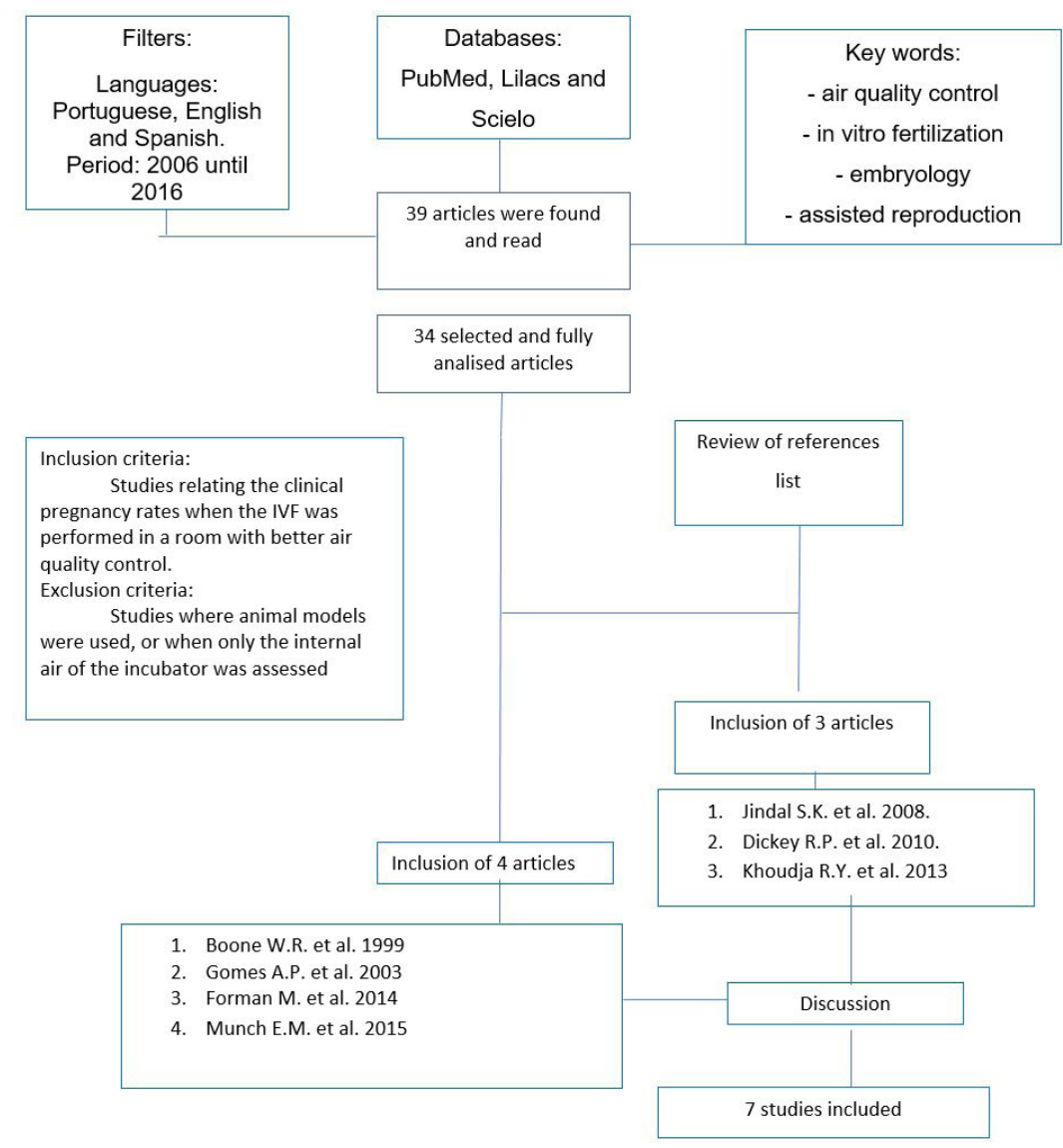

Figure 1. Flow chart of used methodology in the systematic review.

\section{Results}

There were found 39 published articles and upon the reading of their abstracts, 34 were selected and fully read.

It was included 4 studies. Reviewing their reference lists, other 3 studies were selected and included.

Among the studies 5 were from USA, 1 from Brazil and 1 from China.

All studies used air filters in order to obtain a good environment quality inside the laboratory. It was used HEPA or VOC filters, and their association (Table 1).

There was only one study where the HEPA filter was not used, and it was the only without an increase in IVF and clinical pregnancy rates. 
Table 1. Analyzed studies, overview

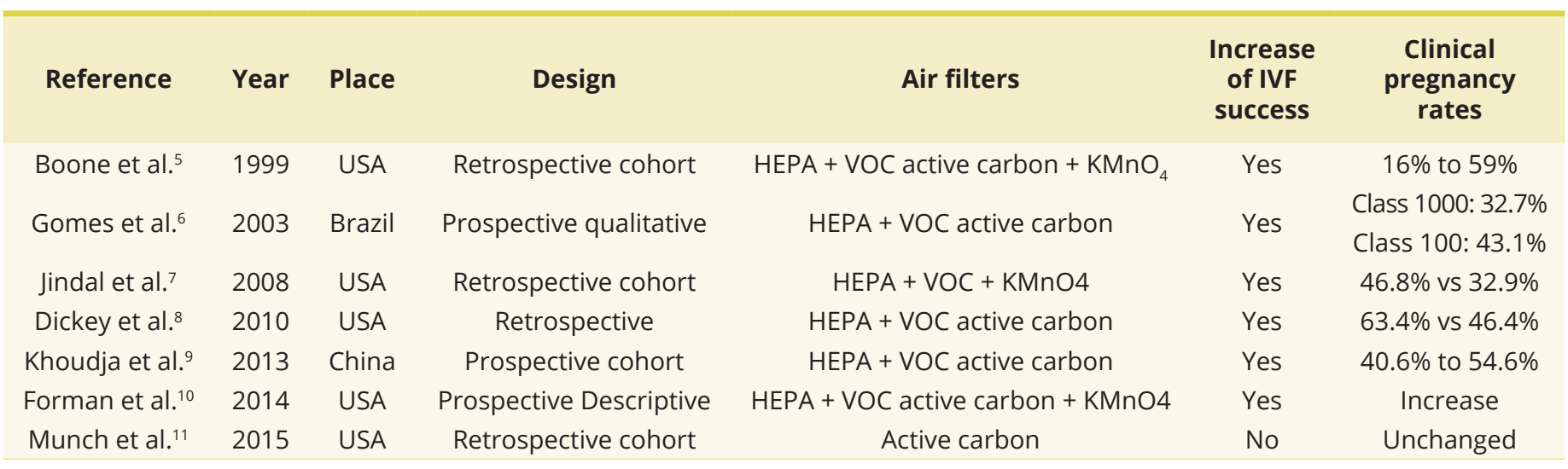

\section{Discussion}

In a retrospective cohort study with 275 couples that underwent IVF between 1993 and 1997, Boone et al. ${ }^{5}$ observed that the pregnancy rate presented a decline of $45 \%$ in 1993 to $16 \%$ in 1994, when odours and vapours were inserted in the laboratory. The pregnancy rate had a slight increase to $20 \%$ in 1995 after implementation of a clean room, and severely in 1996 and 1997 to 25\% and 59\% respectively. Important variables such as mother's age, initial sperm concentration, percentage of patients submitted to ICSI, percentage of women over 39 years old and reasons leading to IVF procedures did not differ between the groups. This study therefore supports the premise that volatile compounds decrease the implantation and pregnancy rates in IVF programs.

Another publication had similar result. Gomes et al. ${ }^{6}$ realized a prospective qualitative study with 468 ICSI cycle performed between April 2000 and December 2003. The cycles were divided accordingly with the place where they were held: IVF class 1.000 laboratory (ISO 6; $n=220$ ) or class 100 (ISO 5; $n=248$ ). The class 1.000 laboratory was equipped with positive pressure and terminal HEPA filters, in addition to a VOC and particles decontamination unit. In the Class 100 laboratory an air treatment central composed of a positive pressure system, terminal HEPA filters and active carbon filters impregnated with potassium permanganate were used to filter and remove the particles and VOCs from IVF laboratory and adjacent areas: surgical center (class 1.000), changing room and embryo transfer room (class 10.000). In both laboratories, HEPA filters with active carbon were installed between the $\mathrm{CO}_{2}$ supply system and the incubators. It was noticed that a clean room class 100 (ISO 5) with a treatment of the environmental air for the gamete micromanipulation and embryo culture significantly increased the cleavage rates, embryo quality and pregnancy rates. There was also a decrease in the spontaneous abortion rates.

In a retrospective cohort of 2008 Jindal et al. ${ }^{7}$ collected data of patients for 10 months prior $(n=201)$ and after $(n=173)$ the building of a new laboratory. The old laboratory was projected for fresh air uptake only. The new laboratory has hermetical sealing and was planned with air change, positive pressure, HEPA and potassium permanganate filters. The variables remain unchanged between the periods of time. Despite the smaller number of embryos transferred after the construction ( 2.9 versus 3.1 ), the clinical pregnancy rate was statistically higher in the controlled environment group (46.8\% versus $32.9 \%$ ). The pregnancy rates of women bellow the age of 38 years was the most affected by the engineering controls (54.1\% versus $37.5 \%)$. The analysis showed that the engineering controls after the constructions were associated with higher rates of pregnancy rates (OR 1.94, 95\% Cl: 1.2-3.2, p<0.01) after adjusting for age, FSH, number of transferred embryos, sperm motility, number of recovered oocytes and number of embryos at day three.

Dickey et al. ${ }^{8}$ conducted a retrospective study of the fertilization and early pregnancy rates for all patients of IVF and ICSI with age bellow 45 years old. The variables were compared for the 36 months before and 15 months after the occupation of a new IVF laboratory that incorporated improvements to the air quality. In the old laboratory there was less air vents for air change and after 03/18/2007 the new laboratory started to count with an air-filtering unit with HEPA and active carbon filters, designed for IVF laboratory use. The results were compared in three periods of time: I old laboratory (01/01/2006 to $01 / 18 / 2007 n=102)$, II old laboratory $(03 / 19 / 2007$ to $12 / 31 / 2008 n=120)$, III new laboratory $(01 / 01 / 2009$ to $03 / 15 / 2010 n=102)$. The implantation and clinical pregnancy rates were significantly higher in the group III. Thus, the environment air quality affected the gamete and embryo quality when they were outside of the incubator controlled environment.

Accordingly with Khoudja, ${ }^{9}$ based on a prospective cohort study, the air quality it is crucial for IVF success, given the presence of VOCs and microorganisms in laboratory air may be harmful to the embryo's in vitro development. To do so, the study with 1403 cycles of assisted reproduction has instituted IVF laboratories supplied with HEPA and active carbon filters, in addition to positive pressure for air particles, with or without VOC filters. This article also introduces a new technology that uses a honeycomb array for air purification. There was a clear decline in some VOCs such as formaldehyde, ethylene, acetylene, propylene, $\mathrm{SO}_{2}$ pentane, NOx, benzene, Hallon-1211, CGC and alcohol. At the same time, a significant difference was found in some parameters between the third testing time $\Pi 13$ after the carbon filter change and Landson system installation and the first testing time $T 11$ 
before carbon filter change. The differences were on fertilization rate $83.7 \%$ vs $70.1 \%$, embryo cleavage rate $97.35 \%$ vs $90.8 \%$, day 5 blastocyst formation rate $51.1 \%$ vs $41.7 \%$, pregnancy rate $54.6 \%$ vs $40.6 \%$ and implantation rate $34.4 \%$ vs $26.4 \%$.

Forman ${ }^{10}$ carried out a prospective descriptive study in an IVF laboratory equipped with a central air purification system that includes a HEPA filtration, active carbon filters and potassium permanganate. Also, the corridor outside the laboratory was equipped with an unfiltered air system. A central filtration system were suggested to reduce the concentrations of aldehydes, VOCs, and particle in the IVF laboratory. Moreover, reductions in those parameters were observed after the CODA tower. It was highlighted that the increase in the concentration of acetonitrile inside the laboratory was probably due to off gassing of the plastic sheeting used to seal door and air vents.

In a retrospective cohort study of 2015, Munch et al. ${ }^{11}$ analyzed assisted reproduction cycles. The embryo development and the results based in the cycles were compared between three groups: 1) when there was carbon filtration; 2) when there was not carbon filtration; 3) when the carbon filtration was restored. Rates of fertilization, cleavage and blastocyst formation declined during the absence of carbon filtration, and recovered after the re-introduction of the filtration. However, cryopreserved embryos that were thawed and afterwards cultured were similar in cleavage or blastocyst conversion rates with or without the carbon filtration. Clinical pregnancy and live birth rates were similar among the three time periods.

For Morbeck, ${ }^{12}$ there is a lack of evidence for better practice, since informal reports relating the air quality and IVF success rates have resulted in recommendations or small directives for laboratory's operation based in clean rooms standards with little attention to air chemical filtration. Thus a new industry of expensive and specialized air management equipment for IVF laboratories has emerged to provide air quality solutions that were not yet clearly verified. The clinics are incorporating such technology because their embryology laboratories became epicenters of assisted reproduction technology, as IVF practices have become increasingly specialized. Besides, the laboratory's capacity of culture, biopsy and blastocyst freezing it's a rate-limiting step that depends on technical proficiency and supportive and stable culture environment with high quality of air. The air quality may affect the IVF results, however there are few controlled studies about the quality of the air. As a result, the scope is left with minimal industry standards and costly solutions that are not evidence based.

\section{Conclusion}

The reviewed studies have shown a trend of improvement in pregnancy rates due to introduction of air filters in IVF laboratories (Table 2). Apparently, the higher the level of ambient pollution control and VOCs elimination in those places, the higher the IVF success rate. If on one side there is few evidence that the particle filtration itself improves the IVF results, on the other side, available studies suggest that filtration systems should focus, exhaustively, on VOCs elimination. New studies are necessary for effectively access the benefits of air filtration systems with their costs.

Table 2. Presentation of results found in systematic review

\begin{tabular}{|c|c|c|c|c|c|c|}
\hline Boone et al. ${ }^{5}$ & 1993-1997 & Yes & Class 1000 - Class 100 & $16 \%-59 \%$ & $\begin{array}{l}\text { Fertilization rates } \\
60.2 \%-74.1 \%\end{array}$ & $\begin{array}{c}\text { Number of } \\
\text { transferred } \\
\text { embryos } \\
\text { (mean) } \\
\text { n/a* }\end{array}$ \\
\hline Gomes et al. ${ }^{6}$ & $2000-2003$ & Yes & Class 1000: & $32.7 \%$ & $70 \%$ & 3.4 \\
\hline Jindal et al. ${ }^{7}$ & $\mathrm{n} / \mathrm{e}^{*}$ & Yes & Class 100: & $46.8 \%$ & $\begin{array}{c}\text { There was not } \\
\text { significant difference }\end{array}$ & 2.9 \\
\hline \multirow{3}{*}{ Dickey et al. ${ }^{8}$} & \multirow{3}{*}{$2006-2009$} & \multirow{3}{*}{ Yes } & Class 1000: & $44.1 \%$ & $74 \%$ & 8.8 \\
\hline & & & Class 1000 + class $100:$ & $46.4 \%$ & $73 \%$ & 5.8 \\
\hline & & & Class 100: & $63.4 \%$ & $81 \%$ & 1.0 \\
\hline \multirow{2}{*}{ Forman et al. ${ }^{10}$} & \multirow{2}{*}{$n / e^{*}$} & \multirow{2}{*}{ Yes } & Class 1000: & $\mathrm{n} / \mathrm{a} *$ & $\mathrm{n} / \mathrm{a} *$ & $\mathrm{n} / \mathrm{a}$ * \\
\hline & & & Class 100: & $\mathrm{n} / \mathrm{a} *$ & $\mathrm{n} / \mathrm{a} *$ & $\mathrm{n} / \mathrm{a} *$ \\
\hline \multirow{3}{*}{ Munch et al. ${ }^{11}$} & \multirow{3}{*}{$2010-2012$} & \multirow{3}{*}{ tes } & Class 100: & $56.3 \%$ & $64 \%$ & 2.3 \\
\hline & & & Class 1000: & $50.3 \%$ & $59 \%$ & 2.2 \\
\hline & & & Class 100: & $56.1 \%$ & $65 \%$ & 2.4 \\
\hline
\end{tabular}




\section{References}

1. Cohen J, Gilligan A, Esposito W, Schimmel T, Dale B. Ambient air and its potential effects on conception in vitro. Hum Reprod. 1997;12(8):1742-9. PMid:9308805. http://dx.doi.org/10.1093/humrep/12.8.1742.

2. Bento FC and Esteves S. Implementation of cleanroom technology in reproductive laboratories: the question is not why but how. Reprod Biomed Online. 2016;32(1):9-00311. PMid:26602944. http://dx.doi.org/10.1016/j.rbmo.2015.09.014.

3. Esteves SC, Bento FC. Air quality control in the ART laboratory is a major determinant of IVF success. Asian J Androl. 2016;18(4):596599. PMid:26585700. http://dx.doi.org/10.4103/1008-682X.166433.

4. Esteves SC, Bento FC. Implementation of air quality control in reproductive laboratories in full compliance with the Brazilian Cells and Germinative Tissue Directive. Reprod Biomed Online. 2013;26(1):9-21. PMid:23177417. http://dx.doi.org/10.1016/j. rbmo.2012.10.010.

5. Boone WR, Johnson JE, Locke AJ, Crane MM 4th, Price TM. Control of air quality in an assisted reproductive technology laboratory. Fertil Steril. 1999;71(1):150-4. PMid:9935133. http://dx.doi.org/10.1016/S0015-0282(98)00395-1.

6. Gomes AP Junior SV, Esteves S. O controle da poluição do ar no laboratório de fertilização in vitro e áreas adjacentes melhora as taxas de formação de embriões, clivagem e de gravidez e diminui a taxa de aborto: comparação entre salas limpas classe 100 (ISO 5) e classe 1.000 (ISSO 6). 2003.

7. Jindal SK, Polotsky AJ, Buyuk ER, Lieman HJ, Gilligan A. Improved pregnancy rates following introduction of engineering controls of lab air quality. Fertil Steril. 2008;90(Suppl):S403. http://dx.doi.org/10.1016/j.fertnstert.2008.07.1412.

8. Dickey RP, Wortham JWE Jr, Potts A, Welch A. Effect of IVF laboratory air quality on pregnancy success. Fertil Steril. 2010;94(4):S151. http://dx.doi.org/10.1016/j.fertnstert.2010.07.605.

9. Khoudja RY, XU Y, Li T, Zhou C. Better IVF outcomes following improvements in laboratory air quality. J Assist Reprod Genet. 2013;30(1):69-76. PMid:23242648. http://dx.doi.org/10.1007/s10815-012-9900-1.

10. Forman M, Sparks AET, Degelos S, Koulianos G, Worrilow KC. 10 Statistically significant improvements in clinical outcomes using engineered molecular media and genomically modeled ultraviolet light for comprehensive control of ambient air (AA) quality. Fertil Steril. 2014;102(3):e91. http://dx.doi.org/10.1016/j.fertnstert.2014.07.307.

11. Munch EM, Sparks AE, Duran HE, Van Voorhis BJ. Lack of carbon air filtration impacts early embryo development. J Assist Reprod Genet. 2015;32(7):1009-17. PMid:26003657. http://dx.doi.org/10.1007/s10815-015-0495-1.

12. Morbeck DE. Air quality in the assisted reproduction laboratory: a mini-review. J Assist Reprod Genet. 2015;32(7):1019-24. PMid:26238385. http://dx.doi.org/10.1007/s10815-015-0535-x.

\section{*Correspondence}

Bruna Sabbag Pontes

Pontifícia Universidade Católica de Goiás (PUC), Faculdade de Medicina, Ambulatório de Infertilidade

Rua T36, n 3485, Ed Solar Tocantins, Setor Bueno

CEP 74223-055, Goiânia, GO, Brazil

Tel.: +55 (60) 98129-8364

E-mail: brunasabbagpontes@gmail.com

\section{Authors information}

BSP - Physician graduated at Pontifícia Universidade Católica de Goiás (PUC). MLPR - Physician graduated at Pontifícia Universidade Católica de Goiás (PUC). ECC - women's health unity; medicine graduation, Pontifícia Universidade Católica de Goiás (PUC); Associate Director of Humana Medicina Reprodutiva.

\section{Authors contribution}

BSP and MLPR participated actively in the process of choosing and analyzing articles, besides the writing and revision of the final work. ECC oriented the process of construction, analysis and review of the written work. 